\title{
O IFMS - CAMPUS TRÊS LAGOAS - CONTRA A REFORMA DO ENSINO MÉDIO
}

\section{THE IFMS - TRÊS LAGOAS CAMPUS - AGAINST HIGH SCHOOL REFORM}

\author{
Renata Moreira Delgado ${ }^{1}$ \\ Tarcísio Luiz Pereira²
}

\begin{abstract}
RESUMO: Este estudo analisa as contradições existentes entre a Reforma do Ensino Médio promovida pela Lei 13.415 de 2017 e a política de Educação Integrada realizada pelos Institutos Federais, mormente o campus Três Lagoas. Pretende-se expor e analisar essa oposição fundamentando-se nos dispositivos legais que garantem autonomia didático-pedagógica a estas instituições, bem como no documento intitulado Diretrizes Indutoras do Ensino Médio Integrado publicado pelo Fórum de Dirigentes de Educação/ Conselho Nacional das Instituições da Rede Federal de Educação Profissional, Científica e Tecnológica (FDE/CONIF) em 2018, que coloca os institutos federais, em sua totalidade, numa posição de incompatibilidade com a nova normativa. Trata-se de pesquisa teórico-documental, com abordagem materialista histórica dialética, fundamentada pela corrente marxista.
\end{abstract}

PALAVRAS-CHAVE: Reforma do Ensino Médio. IFMS/Três Lagoas. Oposição.

\begin{abstract}
This study analyzes the existing contradictions between the Secondary Education Reform promoted by Law 13.415 of 2017 and the Integrated Education policy carried out by the Federal Institutes, especially the Três Lagoas campus. It is intented to expose and analyze this opposition based on legal provisions that guarantee didactic-pedagogical autonomy to these institutions, as well as in the document entitled Guidelines Inducing Integrated High School published by Forum of Education Directors/ National Council of Institutions of the Federal Network of Professional, Scientific and Technological education (FDE/CONIF) in 2018, which places federal institutes in its totality, in a position of incompatibility with the new approach, based on the Marxist current.
\end{abstract}

KEYWORDS: High School Reform. IFMS/Três Lagoas. Opposition.

\section{Introdução}

A reforma do Ensino Médio instituída pela Lei nº 13.415/2017 e expressa no documento da Base Nacional Comum Curricular do Ensino Médio (BNCC-EM) ameaça os princípios de formação integral e a concepção de Ensino Médio Integrado (EMI) que baliza os cursos oferecidos pelos Institutos Federais de Educação, Ciência e Tecnologia (IFs). Diante desta reforma, é preciso construir uma consciência e uma base de resistência, para

\footnotetext{
1 Instituto Federal de Mato Grosso do Sul, Brasil. E-mail: renata.delgado@ifms.edu.br

(i) https://orcid.org/0000-0002-1423-3740

2 Universidade Federal de Mato Grosso do Sul, Brasil. E-mail: tarcisio.pereira@ufms.br

(iD) https://orcid.org/0000-0002-2294-3742
}

- Informações completas da obra no final do artigo 
que se possa reagir por meio das práticas pedagógicas, contra o desmonte da educação pública no país.

O objetivo deste trabalho é identificar as contradições que existem na reforma proposta e aprovada em 2017, e evidenciar que a sua implementação na rede federal, mormente nos institutos federais, é amplamente contraditória. Há elementos conflitantes em diversos aspectos dispostos na Lei 13.415 em relação ao princípio da autonomia dos institutos federais, bem como da produção dos atos normativos destas instituições.

Não obstante, ainda que haja muito que avançar para que os institutos federais contemplem uma educação integrada em seu sentido pleno, temos legislação e um conjunto de diretrizes que apontam na direção desta educação integrada. A educação integrada compreendida neste trabalho considera dois sentidos sugeridos por Marise Ramos (2007). O primeiro sentido da formação integrada é o da formação omnilateral. Este sentido é filosófico e expressa uma concepção de formação humana, com base na integração de todas as dimensões da vida no processo formativo. Este "primeiro sentido da integração ainda não considera a forma ou se a formação é geral ou profissionalizante" (RAMOS, 2007, p. 3). Neste sentido filosófico, a integração possibilita formação omnilateral dos sujeitos, pois implica a integração das dimensões fundamentais da vida que estruturam a prática social. Essas dimensões são o trabalho, a ciência e a cultura. $O$ trabalho compreendido como realização humana inerente ao ser (sentido ontológico) e como prática econômica (sentido histórico associado ao respectivo modo de produção); a ciência, compreendida como os conhecimentos produzidos pela humanidade, que possibilita 0 contraditório avanço produtivo; e a cultura, que corresponde aos valores éticos e estéticos que orientam as normas de conduta de uma sociedade.

É preciso compreender o trabalho como princípio educativo. E compreendê-lo desta forma significa compreender que é indissociável a relação entre este (o trabalho), a ciência e a cultura. O trabalho enquanto princípio educativo não é sinônimo de formar para o exercício do trabalho. Considerar o trabalho como princípio educativo equivale dizer que o ser humano é produtor de sua realidade e, por isto, se apropria dela e pode transformá-la.

O segundo sentido da formação integrada, sugerido pela autora, é o da a indissociabilidade entre educação profissional e educação básica. Este segundo sentido é definido como as formas de integração do ensino médio com a educação profissional. Do ponto de vista da política nacional, temos como dispositivo legal o Decreto n 5.154/04, que 
estabelece a Educação Profissional articulada e integrada ao Ensino Médio, como uma possibilidade. Entretanto, é necessário entender que, segundo Frigotto (2005) a profissionalização no ensino médio é uma imposição da realidade, pois na imensa maioria dos municípios e regiões do Brasil, a situação da classe trabalhadora é muito mais degradante do que a situação da classe trabalhadora dos países de capitalismo central ou hegemônicos, que tiveram a experiência do estado de bem-estar social ${ }^{3}$ e a garantia de diversos direitos fundamentais. Ao contrário, na realidade brasileira a imensa maioria das famílias precisam que seus jovens trabalhem muito antes de completarem a maioridade, pois é a única forma de garantir o sustento das famílias, ao custo de baixa escolaridade e sem qualificação profissional.

Diante dessa afirmativa, Ramos assevera que:

[...] não podemos dizer que no Brasil a juventude brasileira oriunda da classe trabalhadora pode adiar para depois da educação básica ou do ensino superior o ingresso na atividade econômica. Enquanto o Brasil for um país com as marcas de uma história escrita com a exploração dos trabalhadores, no qual estes não têm a certeza do seu dia seguinte, o sistema sócio-político não pode afirmar que o ensino médio primeiro deve "formar para a vida", enquanto a profissionalização fica para depois. A classe trabalhadora brasileira e seus filhos não podem esperar por essas condições porque a preocupação com a inserção na vida produtiva é algo que acontece assim que os jovens tomam consciência dos limites que sua relação de classe impõe aos seus projetos de vida (RAMOS, 2007, p. 11).

A partir do decreto supracitado (5.154/2004), dispositivo legal cuja formulação se deu sob intensas e polêmicas discussões políticas e teóricas entre os defensores da educação integrada e setores empresariais ${ }^{4}$, foi resgatada a possibilidade de se tentar desenvolver a educação integrada, com o objetivo de possibilitar que os sujeitos tenham uma formação que, conquanto garanta o direito à educação básica também possibilite a formação para o exercício profissional. Este sentido equivale à indissociabilidade entre educação profissional e educação básica, aludido pela autora.

Inequivocamente, a forma integrada de oferta do ensino médio com a educação profissional é coerente com o primeiro sentido da integração sugerido pela autora e

\footnotetext{
${ }^{3}$ O Estado de Bem-Estar Social consiste num conjunto de políticas públicas que tem o Estado como principal responsável por promover o bem-estar da população. Educação, saúde pública, moradia, seguridade social e renda básica estão dentre estas políticas e muitas delas se tornaram direitos sociais e civis em diversos países durante o século XX, principalmente nos países ditos desenvolvidos (Grifo nosso).

${ }^{4}$ O Decreto no 5.154/2004 aponta para a possibilidade de integração entre o EM e a Educação profissional, mas mantém as outras duas possibilidades de articulação previstas no Decreto ํㅡ 2.208/1997, as formas subsequente e concomitante. (Grifo nosso)
} 


\section{ENSIN@UFMS 2021}

ISSN 2525-7056

obedece a algumas diretrizes ético políticas: integração de conhecimentos gerais e específicos; construção do conhecimento pela mediação do trabalho, da ciência e da cultura; utopia de superar a dominação dos trabalhadores e construir a emancipação formação de dirigentes (RAMOS, 2007).

Sob esses princípios, é importante compreender que o ensino médio é a etapa da educação básica em que a relação entre ciência e práticas produtivas se evidencia. Logo, é a etapa biopsicológica e social dos estudantes em que ocorre o planejamento e a necessidade de inserção no mundo do trabalho, no mundo adulto. Disto decorre o compromisso com a necessidade dos jovens de terem a formação profissional mediada pelo conhecimento.

Tomando tais concepções como pressupostos, o primeiro tópico deste estudo abordará a reforma do ensino médio instituída pela Lei oㅜ 13.415/2017, o segundo tópico deste texto versará sobre a oposição entre a política educacional do IFMS e a reforma, bem como dos movimentos de resistência assumidos pelos defensores da educação integrada e dos institutos federais, com base na relativa autonomia que desfrutam estas instituições outorgadas pela sua lei de criação, a lei n. - 11.892/2008, o terceiro tópico analisará a estrutura curricular dos cursos de ensino médio integrado oferecidos pelo IFMS campus Três Lagoas e em que medida essa estrutura foi mantida em oposição a reforma promovida pela lei oํ 13.415/2017.

\section{A Reforma do Ensino Médio: retrocesso nas políticas educacionais brasileiras}

Completando duas décadas no ano de 2016, a Lei de Diretrizes e Bases da Educação (LDB) recebeu uma proposta de alteração por meio de Medida Provisória (MP no 746/2016). Tal ato denotava o caráter de urgência por uma reforma do Ensino Médio (EM), sob a justificativa de que o atual currículo desta etapa do ensino apresentava-se rígido demais e precisava ser alterado por outro mais flexível e mais dinâmico. A proposição da reforma também aludia que era necessário valorizar o protagonismo dos jovens por meio do estabelecimento dos itinerários formativos que permitiria ao aluno "escolher" o processo de formação que desejaria seguir.

De acordo com Moura (2017) a Lei está abrigada por uma racionalidade maior, que alberga um conjunto de medidas, em curso ou em elaboração, cujo objetivo é reconfigurar o Estado brasileiro no sentido de torná-lo ainda "mais mínimo" no que se refere às garantias 
dos direitos sociais e "mais máximo" para regular os interesses do grande capital nacional e internacional, especialmente o financeiro/especulativo. Trata-se, assim, de uma nova fase de radicalização do neoliberalismo.

Ao centrar o foco na organização curricular, a reforma omite e negligencia a questão fulcral que afeta a qualidade do EM no país. Que de acordo com o autor são:

\begin{abstract}
A falta de infraestrutura que garanta o funcionamento qualificado das escolas públicas, destacando-se: ausência de instalações físicas adequadas, bibliotecas, laboratórios, espaços para a prática esportiva e de atividades artístico-culturais; inexistência de quadro de professores e demais trabalhadores da educação contratados por concurso público; planos de carreiras e de formação, salários dignos e condições de trabalho adequadas (MOURA, 2017, p. 120).
\end{abstract}

Além de desconsiderar estas questões, a reforma agrava a fragmentação, a hierarquização social e a qualidade do EM. A organização proposta reforça a dualidade educacional e social que caracteriza historicamente o país e potencializa a subtração de direitos da classe trabalhadora. Sobretudo, ataca a concepção de formação humana integral e conduz o EM a uma lógica mercadológica. Ferreti assevera que:

[...] a MP 746 é, na verdade, a etapa semifinal de um processo iniciado em 2013 (ainda no governo Dilma) por meio de um Projeto de Lei (6840/2013) apresentado por uma Comissão Especial da Comissão de Educação da Câmara dos Deputados (FERRETI, 2018, p. 26).

Tal projeto de lei foi alvo de questionamentos por parte da sociedade civil, especialmente do Movimento em Defesa do Ensino Médio, entretanto diversos elementos dele mantiveram-se presentes na Lei 13.415, com algumas modificações, o principal dos quais se refere à constituição dos denominados itinerários formativos. De acordo com a reforma, o art. 36 da LDB passa a determinar que o currículo do ensino médio será composto pela Base Nacional Comum Curricular (BNCC) e por itinerários formativos, que serão organizados por meio da oferta de diferentes arranjos curriculares, divididos em cinco áreas: I - linguagens e suas tecnologias; II - matemática e suas tecnologias; III - ciências da natureza e suas tecnologias; IV - ciências humanas e sociais aplicadas e; V - formação técnica e profissional. No $\S 1$ do referido artigo a lei explicita que a organização e oferta destes itinerários ficam a critério dos sistemas de ensino.

Num outro estudo (FERRETI, 2016) relata que o referido projeto, apesar de remeter à reformulação do ensino médio, o que supõe a abordagem dos vários aspectos que a ele se referem, centra, de fato, suas atenções no currículo. O pretendido é a modificação da 


\section{ENSIN@UFMS 2021}

ISSN 2525-7056

LDB 9394/96 e, por extensão, das Diretrizes Curriculares Nacionais do Ensino Médio (DCNEM) aprovadas em 2011.

Tendo este processo resultado na Lei 13.415/2017, a reforma curricular engendrada e em vigor hodiernamente, objetiva tornar o currículo mais flexível e apoia-se em duas justificativas, a saber: A baixa qualidade do Ensino Médio ofertado no país; A necessidade de torná-lo atrativo aos estudantes em face dos índices de abandono e reprovação. discurso oficial fez uma política de total ineficiência do EM e omitiu as experiências positivas, particularmente as do Ensino Médio Integrado (EMI) realizado na rede federal, especialmente nos Institutos Federais. Nos índices de avaliação do Exame Nacional do Ensino Médio (ENEM) e do Programa Internacional de Avaliação de Alunos (Pisa), que embora, numa perspectiva de formação omnilateral não seja um modelo de avaliação coerente, o primeiro é o exame de larga escala oficial tido como métrica não só para avaliar o ensino médio no país, mas também para classificar e permitir o acesso ao Ensino Superior e às universidades públicas e privadas; o segundo, exame internacional que avalia os sistemas de ensino em todo o mundo. Tais exames evidenciaram, que os alunos dessas escolas obtiveram médias superiores às nacionais e, em alguns casos, às de alunos de países da Organização para a Cooperação e Desenvolvimento Econômico (OCDE). Desde 2015 os institutos federais têm figurado no topo do ranking do ENEM, em diversos estados do país, superando inclusive, as escolas particulares.

A esse respeito, Moura (2017) considera contraditório que autoridades públicas e representantes do capital, que se utilizam desses exames e indicadores para fazer crítica à educação pública e apologia à privada, omitam os dados positivos alcançados por alunos de escolas públicas, a partir dos mesmos indicadores e exames. Um fato ilustrativo do exposto é que em 2015 o Instituto Nacional de Estudos Pesquisas (INEP) ocultou os institutos federais da lista de divulgação dos resultados do Enem daquele ano. Diversos questionamentos foram levantados e muitas notas solicitando esclarecimentos foram enviadas ao INEP pelo Conselho Nacional das Instituições da Rede Federal de Educação Profissional, Científica e Tecnológica (CONIF). Os institutos federais estariam prejudicando o brilho das escolas particulares no ranqueamento do exame? Ou estariam incomodando por mostrarem que quando há investimento e boas condições de trabalho é possível oferecer educação de maior qualidade para os jovens da classe trabalhadora? A despeito 
desses e outros questionamentos o INEP se retratou e alegou erro ao fazer o lançamento dos dados no sistema (TRIBUNA DO NORTE, 2016).

Ao desconsiderar tais experiências positivas, a reforma preconizou a fragmentação do EM mediante a estruturação que estabeleceu a organização do currículo por meios dos itinerários formativos. Ao promover o fatiamento do conhecimento em itinerários distintos, a reforma se contrapõe a concepção de Ensino Médio como a etapa final da Educação Básica, conforme dispõe a LDB. E ainda, se contrapõe aos princípios constitucionais que trazem a educação e a universalização da Educação Básica como direitos subjetivos (CF, 1988). Neste sentido Moura afirma que "a reforma promove a redução de conteúdos formativos em cada um dos itinerários formativos propostos" (2017, p. 121). Dito de outro modo, nega o Ensino Médio enquanto etapa final da Educação Básica.

A respeito da flexibilização curricular proposta pelos itinerários, Ferreti afirma que:

A legislação parece ignorar que a divisão das atuais matrizes curriculares em um núcleo comum e uma parte diversificada, tendo em vista 0 atendimento às demandas locais por parte das escolas, devidas à extensão e diversidade cultural do país, já se constitui, em certo sentido, numa forma de flexibilização, aceita e praticada pelas escolas brasileiras desde a década de 1980, a qual não priva os estudantes do acesso ao conjunto de conhecimentos ofertados a partir de vários campos do conhecimento historicamente produzido (FERRETI, 2018, p. 27)

A flexibilização proposta na lei por meio dos itinerários serão estipulados pelo sistema de ensino de cada ente federativo. Tal flexibilização possibilita, na análise do autor, que

[...] em face do atual contexto econômico e político do país, de que seja limitada a referida flexibilização dos itinerários formativos pelos estados, na medida em que, de acordo com o espírito da Lei, os Conselhos Estaduais de Educação de cada ente possam ser, de certa forma, pressionados para oferecer prioritariamente, ou em maior número, itinerários formativos mais afinados com a perspectiva dos interesses econômicos, quais sejam, os referentes às áreas das Ciências Naturais, Matemática e Linguagens (FERRETI, 2018, p. 28).

O argumento evidenciado acima pode ser reforçado pelo fato da reforma eliminar a obrigatoriedade de alguns componentes curriculares como Educação Física, Artes, Filosofia e Sociologia, os quais poderão fazer parte do currículo sob a forma de estudos e práticas, conforme dispõe o art. 35-A § 2. "A Base Nacional Comum Curricular referente ao ensino médio incluirá obrigatoriamente estudos e práticas de educação física, arte, sociologia e filosofia" (BRASIL, 2017). O termo "estudos e práticas" não apresenta nenhuma 
orientação complementar por parte do legislador, o que, considerando o espírito da lei, nesses moldes não garante um espaço oficial para essas disciplinas no currículo e ainda, pode criar um grave problema quanto ao exercício profissional, uma vez que abre a possibilidade de profissionais com diferentes habilitações desenvolverem os conteúdos inerentes a essas áreas de conhecimento.

Na sequência, no $§ 3$ estipula como obrigatórios durante os três anos do Ensino Médio, apenas os componentes curriculares de Língua Portuguesa e Matemática, seja como parte da formação geral, seja sob a forma de itinerário formativo. Para Ferreti, essa prescrição é justificável, de um lado, porque são componentes curriculares cujo domínio interfere na aquisição de conhecimentos e, segundo o espírito da Lei, no desenvolvimento de competências e habilidades, concernentes a outros componentes curriculares e tem, portanto, forte caráter instrumental.

A flexibilização proposta pela Lei 13.415/2017 não é apenas quantitativa, mas principalmente qualitativa, o que permite interpretá-la como uma ação e proposição afirmativa da busca pela hegemonia da burguesia brasileira, também no campo educacional.

Os pressupostos nela contidos implicam novas exigências no âmbito da formação da força de trabalho em função das necessidades postas pela mesma. $E$, nas expectativas das empresas a respeito de seu atendimento, razão pela qual foram produzidas, de um lado, novas demandas feitas pelo empresariado do setor ao campo educacional e, de outro, o deslocamento do conceito de qualificação profissional, de base principalmente sociológica e adequado à forma de organização da produção e da gerência de caráter taylorista-fordista, para a noção de competência, de base predominantemente psicológica e mais compatível com a forma toyotista (FERRETTI e SILVA, 2019). Infere-se, portanto, que, do ponto de vista formativo, a reforma do ensino médio efetivada pela lei 13.415/2017, está estruturada de acordo com tal noção, visando não apenas as competências cognitivas, mas também as competências socioemocionais, de modo a garantir a constituição da sociabilidade da força de trabalho adaptada às novas demandas do capital, seja no âmbito da produção, seja no âmbito dos serviços.

Solapado pelo discurso oficial da flexibilização curricular e do protagonismo dos jovens (conferido pela possibilidade de escolha de um dos itinerários) repousa a concepção mais nefasta da reforma, a redução e o aligeiramento do Ensino Médio pela redução 
qualitativa que impõe ao currículo e a perda da concepção de etapa final da Educação Básica, uma vez que ao instituir itinerários distintos desmantela a concepção de conjunto orgânico e articulado que deve assegurar a mesma formação para todos os estudantes.

\section{A oposição entre a política educacional do IFMS e a Reforma do Ensino Médio.}

De acordo com a lei 11.892/2008 os institutos federais possuem natureza jurídica de autarquia, detentoras de autonomia administrativa, patrimonial, financeira, didáticopedagógica e disciplinar. Sobre a natureza da autarquia, Silva elucida que

A autarquia administrativa é instituída por lei, tornando-se entidade auxiliar e descentralizadora da administração pública, possuindo patrimônio constituído de recursos próprios e autonomia para se organizar conforme as necessidades do serviço que devem executar (SILVA, 2009, p. 18).

A autora esclarece ainda, que o termo autarquia tem origem na noção de poder próprio e relaciona-se ao desenvolvimento do processo de administração do Estado quando atribui personalidade jurídica a serviços de interesse estatal ou da coletividade, entretanto, mantém o controle sobre sua execução. As entidades com natureza jurídica de autarquia não podem legislar para si próprias, devem seguir as leis instituídas pela entidade que a criou. Logo, uma autarquia é uma "instituição pública-estatal dotada de determinado grau de autonomia limitada aos objetivos definidos pelo Estado através de políticas públicas vinculados a sua natureza" (SILVA, 2009, p.18).

Dada a natureza jurídica dos institutos federais é necessário refletir sobre o conceito de autonomia presente na lei que os criou. Segundo a autora citada acima "o conceito de autonomia pressupõe a liberdade de agir ou, em outras palavras, a possibilidade de autogestão, autogoverno, autonormação" (p. 19) e esta autonomia ocorre em sistemas relacionais, sempre em contextos de interdependência. Posto assim, os institutos federais são dotados de autonomia relativa e deverão seguir os princípios e finalidades que the foram atribuídos pela sua lei criação. Para atingir tais finalidades poderá fazer uso de relativos graus de autonomia articuladas ao contexto maior das políticas públicas.

Feita esta análise sobre a autonomia dos institutos federais é necessário interpretar o cumprimento dos dispositivos legais presentes na normativa 13.415/2017 que implicam mudanças curriculares e pedagógicas, observando os aspectos intrínsecos das relações 


\section{ENSIN@UFMS 2021}

ISSN 2525-7056

políticas, normativas e administrativas que são próprias da Rede Federal de Educação Profissional, Científica e Tecnológica (RFEPCT).

Heeren afirma que é preciso reconhecer a relativa autonomia da RFEPCT e que a esta "cabe analisar no âmbito do seu plano de desenvolvimento institucional os interesses internos quanto ao atendimento de forma parcial e/ou integral da política governamental de reforma do ensino médio" (2019, p. 6).

No entendimento do autor, é necessário realizar três análises. A primeira se refere à análise e referenciação das normativas que regem a RFEPCT. A segunda diz respeito ao entendimento das relações de poder existentes entre as diferentes secretarias vinculadas ao MEC - a Secretaria de Educação Básica (SEB) e a Secretaria de Educação Profissional e Tecnológica do Ministério da Educação (SETEC/MEC) - sendo esta última responsável pela coordenação executiva da política de educação profissional e tecnológica no país. E por fim, identificar as possíveis contradições entre objetivos, princípios e finalidades da reforma proposta pela Lei 13.415/2017 e a política de educação profissional técnica de nível médio no contexto da Rede Federal.

Primeiramente, é preciso que se tenha em mente que as finalidades dos Institutos Federais são as referenciadas e estabelecidas na Lei 11.892/08, em consonância com a Lei de Diretrizes e Bases da Educação (LDB), em seus artigos 39 a 42 que tratam da Educação Profissional e Tecnológica, e regimentos específicos da Educação Profissional e Tecnológica.

A lei de criação dos institutos é o documento norteador da sua atuação educacional e de acordo com a mesma, possuem estrutura organizacional própria que possibilita a sua atuação de forma que esta corresponda às suas finalidades e objetivos institucionais. $\mathrm{Na}$ secção IV da referida lei estão definidas as instâncias e colegiados que comporão o organograma dos institutos federais. No IFMS, por ser estruturado de forma multicampi, tem-se uma instância central de tomada de decisões que é composta pelo Conselho Superior (COSUP), formado por representantes de docentes, de discentes, de servidores técnicos, de discentes egressos, de representantes da sociedade civil, de representante do MEC e do Colégio de Dirigentes (CODIR), por meio de eleições bianuais. O COSUP é um órgão colegiado, de caráter consultivo e deliberativo e tem por finalidade regular e aprovar as diretrizes de atuação do IFMS no âmbito acadêmico e administrativo. O CODIR é um órgão de apoio às decisões tomadas pela reitoria, formado pelo reitor, pelos pró-reitores e 
pelo Diretor-Geral de cada um dos campi do IFMS. Neste órgão o caráter é apenas consultivo. A reitoria, órgão executivo da instituição é composta pelo reitor e por cinco próreitores e a esta cabe a administração, a coordenação e supervisão das atividades da instituição. A Reitoria está subordinada ao COSUP, órgão máximo da estrutura.

Em cada campus, tem-se um organograma específico. No IFMS/TL tem-se a figura do Diretor-Geral, cargo executivo máximo, ao qual estão subordinadas as diretorias de administração (DIRAD) e diretoria de ensino, pesquisa e extensão (DIREN). A esta última, estão ligadas as coordenações de cursos e os colegiados de cursos. Esta estrutura é responsável pela organização administrativa, acadêmica, pedagógica e técnica no âmbito do campus. Esta estrutura de órgãos colegiados compõe uma organização políticaadministrativa específica com o propósito de garantir a adequação dos institutos federais aos objetivos e finalidades constantes em sua lei de criação, resguardando-Ihes a autonomia para estabelecer normas internas para o alcance das finalidades.

Afinada à lei de criação dos institutos, temos a Resolução CNE/CEB n. ㅇ 6/2012. Tal resolução define as Diretrizes Curriculares Nacionais para a Educação Profissional Técnica de Nível Médio e traz como princípio norteador a ideia do "trabalho assumido como princípio educativo, tendo sua integração com a ciência, a tecnologia e a cultura como base da proposta político-pedagógica e do desenvolvimento curricular" (BRASIL, 2012). Além disso valoriza os aspectos humanísticos, científicos e tecnológicos com vistas a promoção da formação integral do indivíduo, tomando a pesquisa como princípio pedagógico e assegurando a interdisciplinaridade.

A lei de criação e a resolução que define as diretrizes curriculares são documentos de orientação nacional para os institutos federais. Além desses, o IFMS conta com o Plano de Desenvolvimento Institucional (PDI) no qual é estabelecida a regulamentação interna que normatiza a forma de atuação do instituto no cumprimento das disposições legais hierarquicamente superiores. Desta forma, cada instituto tem a possibilidade de definir e implementar sua política interna de ensino, pesquisa e extensão e desenvolver uma matriz curricular própria dos cursos que oferece.

A segunda análise proposta por Heeren (2019) aponta para o fato de a Educação Profissional e Tecnológica (EPT) estar diretamente sob a égide da SETEC revela uma singularidade importante para observarmos alguns aspectos relacionados à autonomia dos institutos federais. A secretaria, criada em 2004, tem por atribuição formular, implementar, 
monitorar, avaliar e induzir políticas, programas e ações de EPT. Sendo responsável ainda, pela proposição de ações com vistas à concepção e atualização de diretrizes nacionais para a oferta de cursos de educação profissional e tecnológica alinhadas às demandas sociais. De acordo com o autor a criação de uma secretaria específica que regulamenta a Educação Profissional e Tecnológica e organiza a Rede Federal no país "contribui para que a relativa autonomia dos institutos federais, prevista em sua prerrogativa de autarquia federal, seja concretizada em sua completude" (p. 6).

Além de coordenar nacionalmente a política de EPT, a SETEC responde pela criação, manutenção, supervisão e fortalecimento das instituições que compõem a Rede Federal, tendo o dever de considerar as particularidades teóricas do ensino profissional técnico de nível médio, orientando-o de maneira coerente dentro da legislação específica para esse modelo educacional. A importância atribuída a esta secretaria é corroborada pela Resolução n.․ 6, de 20125 , estabelecida pela Câmara de Educação Básica do Conselho Nacional de Educação (CEB/CNE), que define as Diretrizes Curriculares Nacionais para a educação profissional técnica de nível médio, com princípios e finalidades específicos a esta modalidade.

Considerando a importância da SETEC nos papéis de organização e coordenação dos institutos federais, pode-se afirmar que é necessária a participação da mesma junto ao CNE na formulação ou alteração de normativas que indiquem reformas inerentes à ação didática, política e pedagógica dos IFs.

A terceira análise que se propõe a fazer trata-se de identificar as possíveis contradições entre objetivos, princípios e finalidades da reforma proposta pela Lei 13.415/2017 e a política de educação profissional técnica de nível médio no contexto da Rede Federal. A Lei 13.415/17 modificou os artigos da LDB da seção IV, que orientam a educação básica que aborda estritamente o ensino médio propedêutico, mas não alterou os artigos referentes à seção IV-A que aborda especificamente a educação profissional técnica de nível médio. Além disso o parágrafo único do artigo 36-B garante que a Educação

\footnotetext{
${ }^{5}$ O Conselho Nacional de Educação (CNE) demorou 4 anos desde a criação da Rede Federal para emitir as Diretrizes sobre a EPTNM no sentido de regulamentar a oferta do EMI, fato que só ocorreu em 2012, em meio a disputas em torno da concepção de educação profissional, de modo que a Resolução CNE/CEB no 06/2012, que estabeleceu diretrizes curriculares nacionais para a educação profissional técnica de nível médio (DCNEPTNM), reflete tais disputas e apresenta um texto híbrido no qual ora assume-se a defesa da formação humana integral, ora submete a formação humana à lógica das competências para a empregabilidade (CONIF, 2019 - Grifo nosso).
} 
Profissional Técnica de Nível Médio deverá observar: I - os objetivos e definições contidos nas diretrizes curriculares nacionais estabelecidas pelo Conselho Nacional de Educação; II - as normas complementares dos respectivos sistemas de ensino; III - as exigências de cada instituição de ensino, nos termos de seu projeto pedagógico. Deste modo é a Resolução CNE/CEB № 6/2012 que deverá nortear as normas complementares de cada instituto federal, bem como dos projetos pedagógicos de cada unidade educacional ou campus.

Heeren aponta que:

[...] a lei da reforma do ensino médio não explicita as conexões entre as diferentes modalidades/formas de organização curricular (médio integrado; concomitante e subsequente) já definidas na educação profissional e os eixos de formação criados para "o novo ensino médio". Essa diferença não prevista pela reforma do ensino médio na organização curricular traz uma contradição bastante acentuada, sobretudo em relação à perspectiva de formação integral do estudante (HEEREN, 2019, p. 11).

O Fórum de Dirigentes de Ensino (FDE) do Conselho Nacional das Instituições da Rede Federal de Educação Profissional, Científica e Tecnológica (CONIF) vem lutando contra a reforma do ensino médio desde 2014, quando se posicionou contra O PL 6.840/2013 que alterava o Ensino Médio, por entender que tal projeto significava um retrocesso e, sobretudo, uma ameaça ao projeto de Ensino Médio Integrado implantado pela RFEPCT. Em 2016 iniciou a construção de uma Agenda de Fortalecimento do EMI, por meio da elaboração de um documento-base para afirmar o projeto de Ensino Médio Integrado da Rede Federal, seguindo os princípios e definições contidas na Resolução CNE/CEB no 06/2012 e os compromissos da Lei 11.892/2008. Em 2018, construiu uma agenda de fortalecimento do EMI que resultou na construção das Diretrizes Indutoras do EMI.

Essas diretrizes trazem como objetivos precípuos: 1) construir as bases e fundamentos legais que assegurem a continuidade do Ensino Médio Integrado da Rede Federal, em um contexto de ameaças impostas pela reforma do Ensino Médio; 2) afirmar uma visão de Ensino Médio Integrado para os Institutos Federais pautada na formação humana integral e no currículo integrado;3) apresentar conceito de qualidade em educação numa perspectiva social, compreendendo a educação como atividade complexa em que processos e resultados são inseparáveis; 4) recomendar orientações para melhor alinhar e estruturar o projeto de EMI na Rede Federal. 
Dentre as 23 diretrizes que consubstanciam o documento, destacou-se neste estudo, as seguintes:

[...] 5. Garantir, nos projetos pedagógicos de cursos técnicos integrados, todos os componentes curriculares da formação básica, com foco na articulação e na formação humana integral. 6. Assegurar, nos projetos pedagógicos de cursos técnicos integrados, atividades didático-pedagógicas que articulem ensino, pesquisa e extensão. [...] 8. Garantir uma organização curricular orgânica que privilegie a articulação e a interdisciplinaridade entre os componentes curriculares e as metodologias integradoras e possibilite a inserção e o desenvolvimento de componentes curriculares, ações ou atividades, com vistas à promoção da formação ética, política, estética, entre outras, tratando-as como fundamentais para a formação integral dos estudantes. 9. Prever, nos projetos pedagógicos de cursos técnicos integrados, carga horária específica para Prática Profissional Integrada (PPI), a ser desenvolvida ao longo do curso, a fim de promover o contato real e/ou simulado com a prática profissional pretendida pela habilitação específica. Além disso, articular a integração horizontal e vertical entre os conhecimentos da formação geral e da formação específica com foco no trabalho como princípio educativo (CONIF, 2018, p. 16).

No tocante ao cumprimento das 1800 (mil e oitocentas) horas da BNCC estipuladas pela Lei $n^{\circ}$ 13.415/2017, a mesma estabelece no parágrafo $3^{\circ}$ do art. 4ํqu quará a critério dos sistemas de ensino, compor itinerário formativo integrado, que se traduz na composição de componentes curriculares da BNCC e dos itinerários formativos, considerando os incisos I a $\mathrm{V}$ do caput. $\mathrm{O}$ que, de acordo, com as diretrizes em tela, desobriga os cursos de EMI deste engessamento com relação a esta carga horária, uma vez que os conteúdos da base comum se fundem com os conteúdos da base técnica, na perspectiva da integração. Deste modo, o documento salienta que:

[...] o currículo integrado implica articulação entre conhecimentos básicos e conhecimentos técnicos, que, muitas vezes, fundem-se no processo de ensino e aprendizagem vislumbrando a formação humana integral. Nesse sentido, não há que se falar em BNCC nos cursos técnicos integrados, por tratar-se de contrassenso e fragmentação da formação. Além disso, a autonomia didático pedagógica dos institutos possibilita fundamentar a opção pelo currículo integrado na forma como vem sendo desenvolvido na Rede (idem, ibidem, p.12).

Após a publicação destas diretrizes, em setembro de 2018. A última ação do presidente Michel Temer, em 31 de dezembro deste ano, foi enviar ao Congresso um Projeto de Lei (PL) nำ11. 279/2019 para ser aprovado no governo seguinte. O PL tinha como a principal intenção promover mudanças na Lei 11. 982/2008, a lei de criação dos institutos federais. 
As mudanças mais preocupantes contidas no $\mathrm{PL}$ consistiam na retirada da preferência à oferta do ensino médio integrado pelos IFs e o aumento para $70 \%$ da oferta na modalidade de Ensino Médio propedêutico, obviamente um aceno para que os institutos se encaixassem na reforma do ensino médio sancionada em 2017 e que deveria entrar em vigor até 2022. Proibia a oferta de cursos de pós-graduação strictu sensu, em nível de mestrado e doutorado acadêmicos, permitindo apenas mestrados e doutorados profissionais. Além disso, entre outras, estipulava que os Reitores e Diretores-Gerais do campus fossem indicados diretamente pelo governo federal, extinguindo a consulta para a escolha por parte da comunidade e pelos pares. Uma clara tentativa de desmontar o CONIF e acabar com o processo democrático de escolha nas instituições da rede federal.

O CONIF acompanhou as decisões e passos da proposta e em março de 2019 se reuniu no IFMS para a articulação e pedido de retirada da tramitação do PL, que foi referendada pela SETEC/MEC por meio da Nota Técnica ํำ4/2019/DDR/SETEC. No mês seguinte o PL foi retirado de tramitação.

Sendo o IFMS signatário do documento com as diretrizes indutoras do EMI lançadas pelo CONIF, analisaremos no tópico a seguir como o campus Três Lagoas manteve a organização de seus cursos de EMI.

\section{A organização curricular dos cursos de nível médio integrado no IFMS campus Três Lagoas}

O IFMS Três Lagoas oferece dois cursos de nível médio integrado: Técnico em Informática e Técnico em Eletrotécnica. A estrutura curricular destes cursos é dividida em três partes: Núcleo Comum, Núcleo Técnico e Núcleo Articulador.

O Núcleo Comum é composto pelas unidades correspondentes à Formação Geral.

O Núcleo Técnico é composto pelas unidades específicas do curso profissional, que são orientadas pelo Catálogo Nacional de Cursos Técnicos (CNCT).

O Núcleo Articulador é composto por unidades curriculares que tem por objetivo garantir a integração entre os dois primeiros. É composto por unidades curriculares que fomentem a pesquisa, a iniciação científica, projetos de ensino, pesquisa e extensão, práticas profissionais integradoras, práticas desportivas e práticas artístico-culturais.

Para ambos os cursos oferecidos pelo IFMS/TL, o CNCT estabelece 1200 horas referentes à formação técnica. De maneira colegiada, o campus instituiu 1875 horas 
destinadas às unidades curriculares do Núcleo Comum, que são as disciplinas de formação geral (Língua Portuguesa e Literatura Brasileira, Língua Estrangeira Moderna - Inglês, Educação Física, Arte, História, Geografia, Filosofia, Sociologia, Matemática, Física, Química e Biologia). 125 horas para Atividades Diversificadas, o Núcleo Articulador, que podem ser disciplinas optativas; projetos de ensino, pesquisa e extensão; prática profissional integradora; práticas desportivas ou artístico-culturais e ainda, 120 horas de estágio supervisionado. Totalizando, para ambos os cursos, uma carga horária de 3320 (três mil, trezentas e vinte) horas.

Esta estrutura foi revista e aprovada em 2019, após a promulgação da Lei no 13.415/2017 pelos órgãos colegiados do campus e como se pode notar, baseado no documento das diretrizes indutoras emitidas pelo CONIF, não atendeu a obrigatoriedade de oferecer no máximo 1800 horas em disciplinas da formação geral, preconizada pela referida lei.

Analisando a matriz curricular anterior e comparando-a com esta nova versão (de 2019) podemos observar que houve diminuição nas cargas horárias das unidades de Educação Física e Física, entretanto houve aumento das horas destinadas à disciplina de Arte, já Filosofia e Sociologia não sofreram nenhuma alteração. Tais modificações pontuais nas cargas horárias destas unidades curriculares não tem ligação com as imposições da lei ํo 13.415/2017. Tal fato demonstra que o IFMS/TL segue oferecendo seus cursos de Nível Médio Integrado sem sofrer grandes impactos com relação à reforma imposta ao EM no país.

Quanto às unidades curriculares que do Núcleo Técnico ${ }^{6}$ não houve nenhuma modificação e o mesmo continua composto pelas unidades constantes do CNCT de acordo com cada curso, somando - tanto no curso de Informática, quanto no curso de Eletrotécnica -1200 horas.

\footnotetext{
${ }^{6}$ Unidades curriculares específicas do curso integrado em Informática: Algoritmos, Desenvolvimento Web, Informática aplicada, Instalação e Manutenção de Computadores, Banco de dados, Sistemas Operacionais, Frameworks, Programação para Dispositivos móveis, Rede de Computadores, Tópicos especiais em Tecnologia da Informação.

Unidades curriculares específicas do curso integrado em Eletrotécnica: Eletricidade CC, Eletricidade CA, Instalações Elétricas Prediais, Eletrônica Geral, Conversão de Energia, Eletrônica Digital, Máquinas Elétricas e Acionamentos, Eletrônica de Potência, Comandos Elétricos, Sistemas Microcontrolados, Instalações Elétrica Industriais, Acionamentos especiais, Geração, Transmissão e Distribuição de Energia Elétrica, Acionamento Eletropneumático e Eletrohidráulico, Instrumentação e Controle, Automação Industrial. (De acordo com os projetos pedagógicos de cursos - IFMS/TL, 2019)
} 
Finalizando a estrutura curricular dos cursos, no Núcleo Articulador, estão previstas unidades curriculares como: Metodologia de Pesquisa; Informática Aplicada; Comunicação Técnica; Produção Técnica e Científica; Computador, Ética e Sociedade; Estatística; Meio Ambiente e Energias Renováveis; Segurança do Trabalho; Empreendedorismo e Inovação ${ }^{7}$, entre outras. Neste núcleo, além de unidades curriculares voltadas ora para o aperfeiçoamento do núcleo comum, ora para o aperfeiçoamento do núcleo técnico, também são desenvolvidos projetos de pesquisa e extensão, nos quais pode-se destacar vários projetos em andamento no campus Três Lagoas, tais como:

- Projeto de xadrez, Clube de astronomia, Projeto Mulheres na Ciência, entre outros, além de projetos e iniciação científica, nos quais os estudantes podem dar seus primeiros passos na aprendizagem da pesquisa sob a orientação dos professores;

- Práticas desportivas, incluindo treinamentos e atividades em modalidades específicas. O IFMS mantém um projeto denominado Jogos do IFMS (JIFMS) que é um evento esportivo anual, no qual estudantes de todos os campi fazem treinamento esportivo contínuo para participar das etapas locais, regionais, estaduais e nacionais. Ressalta-se aqui o caráter de multimodalidades que são contempladas neste circuito esportivo, fugindo da noção de que somos "o país do futebol". E embora, o campus não possua um centro de treinamento adequado, são desenvolvidas atividades e treinamento de várias modalidades, e as mesmas são incentivadas e tratadas com seriedade pelo grupo docente e técnico do campus, e ainda, consolidadas institucionalmente por meio dos JIFMS. Pode-se dizer, neste aspecto, que o campus Três Lagoas demonstra um razoável esboço do que Marx (1866) denominou de necessidade de educação do corpo aliada à instrução.

- Práticas artístico-culturais, compreendendo a participação em eventos ou projetos de dança, música ou literatura, dentre estas práticas, destaca-se o evento Chá com Letras e Filosofia, outro evento anual exclusivo do campus Três Lagoas que aborda questões atuais para reflexão e proporciona o desenvolvimento do pensamento crítico nos

\footnotetext{
${ }^{7}$ Embora não seja o objetivo deste trabalho analisar os conteúdos trabalhados em cada unidade curricular, a presença desta unidade, em especial, é considerada um desserviço à formação integrada. Posto que hodiernamente, as questões sociais e as mazelas produzidas pelo capitalismo continuam sendo explicadas pelo capital como a falta de educação, de conhecer o mercado e saber como participar ativamente da economia, como falta de planejamento individual e familiar. Logo, o empreendedorismo, com um discurso mais suavizado, afirma a necessidade de desenvolver comportamentos diferenciados para se destacar no mundo dos negócios, para obter sucesso profissional, para ser um "vencedor". Bastante divulgada nos órgãos da mídia e em programas governamentais, a ideologia empreendedora tem ocupado um espaço cada vez maior nas políticas e nos modelos educacionais adotados pelas instituições de ensino. (Grifos Nossos).
} 
estudantes, por meio de atividades que unem a Língua Portuguesa, a Filosofia, a Dança, as Artes, numa abordagem interdisciplinar;

Os projetos contemplam, ainda no que diz respeito ao núcleo articulador, estudos da história e cultura afro-brasileira de caráter contínuo. A instituição possui um núcleo denominado Núcleo de Estudos Afro-brasileiros e Indígenas (NEABI), que promove estudos, palestras e eventos acerca das problemáticas sociais brasileiras que envolvem a comunidade negra e indígena, também desenvolvidos numa perspectiva interdisciplinar, sob a responsabilidade do referido núcleo. Além de projetos de educação ambiental, valorização do idoso, educação alimentar e nutricional.

Não obstante, é importante ressaltar a manutenção da estrutura curricular dos cursos de ensino médio integrado ofertados pelo IFMS/TL foi garantida pela política adotada no IFMS, a partir dos posicionamentos e disputas acirradas pelo CONIF na resistência contra a reforma sancionada pela lei no 13.415/2017.

\section{Considerações Finais}

As elucubrações feitas aqui pretendem provocar um olhar crítico sobre este tema, sem, contudo, apresentar respostas ou conclusões sobre os efeitos da referida reforma, a longo prazo. Em termos de legislação sofremos um grande retrocesso e a disputa pela manutenção dos institutos federais e pelo Ensino Médio Integrado não acabou.

Na contradição, a conquista política da educação também é necessidade do capital, dado o avanço das forças produtivas. Entretanto, essas disputas têm um fundamento filosófico, pois implicam na compreensão do ser humano como capaz de produzir sua existência pelo desenvolvimento de todas as suas potencialidades. A articulação entre trabalho e educação proposta e em certa medida, efetivada pelo IFMS Três Lagoas, representa para os jovens do município e da região, uma ferramenta necessária e importante na busca do atendimento à demanda de formação unitária e politécnica para a classe trabalhadora. Para Marx e Engels (2011) torna-se uma questão de vida ou morte da classe trabalhadora, substituir o ser humano parcial, mero fragmento humano que repete sempre uma operação parcial, pelo indivíduo integralmente desenvolvido.

Diante o exposto, pode-se afirmar que o IFMS Três Lagoas se constitui num "fermento de transformação" (MARX e ENGELS, 2011). Se para os filósofos "não há dúvida de que a conquista inevitável do poder político pela classe trabalhadora trará a adoção do 
ensino tecnológico, teórico e prático nas escolas dos trabalhadores" (idem, p. 98), também não restam quaisquer dúvidas de que a forma capitalista de produção e as análogas condições econômicas dos trabalhadores se opõem fundamentalmente aos "fermentos de transformação" e ao seu objetivo, a eliminação da divisão social do trabalho, tal qual está estabelecida pela ordem.

Não se deve olvidar e deixar que morra o legado marxista de que:

[...] as escolas politécnicas e agronômicas são fatores desse processo de transformação que se desenvolveram espontaneamente na base da indústria moderna; constituem também fatores dessa metamorfose as escolas de ensino profissional onde os filhos dos operários recebem algum ensino tecnológico e são iniciados no manejo prático dos diferentes instrumentos de produção (MARX e ENGELS, 2011, p. 98).

Diante de tantos desafios, há que se considerar o IFMS Três Lagoas como uma importante estratégia para que os jovens da classe trabalhadora tenham acesso às conquistas científicas e tecnológicas da sociedade. O IFMS Três Lagoas é uma instituição inacabada, é ainda, um espaço de disputa. Nos projetos dos cursos analisados, foi possível observar a caracterização de abordagens ora tradicionais, ora voltadas para 0 desenvolvimento de competências e habilidades, mas por vezes têm sua prática voltada para a promoção de atividades de formação crítica e integradora, que se comparada à realidade das instituições de ensino médio no país, principalmente após reforma instituída pela lei $n^{0} 13.425 / 2017$, é a instituição que mais se aproxima do conceito da politecnia, ainda que distantes do seu sentido pleno, conforme a concepção preceituada por RAMOS, a qual se filiou na introdução deste texto.

No bojo desta discussão, é preciso ter em mente que os ataques ao Ensino Médio Integrado continuarão e é preciso lutar pela garantia inconteste da autonomia didáticopedagógica das instituições de ensino na construção de seus currículos, assegurada em lei, com destaque para o artigo 207 da CF/1988, que garante às universidades, logo aos Institutos Federais também, autonomia didático-científica, administrativa e de gestão financeira e patrimonial e obedecerão ao princípio da indissociabilidade entre ensino, pesquisa e extensão. Para os artigos 15, 53 e 54 da LDB/1996 que também asseguram autonomia pedagógica para criar e fixar seus currículos e programas, entre outras. E ainda, pelos artigos $1^{\circ}$ e $2^{\circ}$ da Lei $n^{\circ} 11.892 / 2008$, lei de criação dos institutos federais que 


\section{ENSIN@UFMS 2021}

ISSN 2525-7056

garantem a oferta prioritária de cursos de ensino médio integrado e suas demais características.

Reafirma-se, nesse sentido, que segundo o FDE/CONIF, os cursos que já se adequaram ou estão em processo de readequação às Diretrizes Indutoras do EMI FDE/CONIF, aprovadas pelos Conselhos Superiores dos Institutos Federais, deverão manter e dar continuidade a essa organização didático pedagógica sem riscos de ferir a legislação vigente.

A crítica à técnica é necessária, mas não pode ser a crítica pela técnica em si, mas pela sua limitação imposta pelos valores da sociedade neoliberal. Assim é necessário debater internamente as possibilidades do instituto federal em Três Lagoas, mas não só internamente, é preciso conhecimento e engajamento da comunidade local para que o instituto Três Lagoas, possa contribuir, em sentido ontológico com a emancipação, preparando a consciência dos jovens e familiares para serem portadores dessa consciência crítica. É preciso formar os jovens tecnicamente, e ao mesmo tempo, formar a consciência, expor as contradições, acirrá-las. Por meio do acirramento das contradições pode-se avançar e resistir às políticas neoliberais, pois, como afirmou Marx e Engels (2011) o desenvolvimento das contradições de uma forma histórica de produção é o único caminho de sua dissolução e do estabelecimento de uma nova forma.

\section{Referências}

BRASIL. Constituição da República Federativa do Brasil. Brasília, DF, 1988.

BRASIL. Leis de Diretrizes e Bases - LDB. Lei no 9.394, Brasília, DF, 1996.

BRASIL. Lei no 11.892, de 29 de dezembro de 2008. Institui a rede federal de educação profissional e tecnológica, e cria os Institutos Federais de Educação, Ciência e Tecnologia. Congresso Nacional. Brasília, DF, 2008.

BRASIL. Resolução CNE/CEB no 11, de 12 de junho de 2008. CNCT - Catálogo Nacional de Cursos Técnicos. Brasília: SETEC/MEC, 2008.

BRASIL. Resolução CEB/CNE n $^{\circ} \mathbf{6}$ de 20 de setembro de 2012. Define Diretrizes Curriculares Nacionais para a Educação Profissional Técnica de Nível Médio. Brasília, DF, 2012.

BRASIL. Lei no. 13.415, de 16 de fevereiro de 2017. Dispõe sobre a reforma do ensino médio brasileiro, Brasília DF, 2017. 
CONIF. Diretrizes Indutoras Para a Oferta de Cursos Técnicos Integrados ao Ensino Médio na Rede Federal De Educação Profissional, Científica e Tecnológica. 2018. Disponível em: https://portal.conif.org.br/images/Diretrizes_EMI_-_Reditec2018.pdf. Acesso em: jun. de 2021.

FERRETI, C. J. Reformulações do Ensino Médio. Holos (Natal. Online), v.6, p.71-91, 2016. Disponível em: http://www2.ifrn.edu.br/ojs/index.php/HOLOS/article/view/4988/1570. Acesso em: mai. 2021.

FERRETI, C. J. A reforma do Ensino Médio e sua questionável concepção de qualidade da educação. Estudos avançados. 32 (93), 2018.

FERRETI, C. J; SILVA, M. R. Dos embates por hegemonia e resistência no contexto da Reforma do Ensino Médio. Trabalho Necessário, v.17, n.32, jan, 2019.

FRIGOTTO, G. Educação e Crise do Capitalismo Real. São Paulo: Cortez, 2010.

HEEREN, M. V; SILVA, M. L. da. O princípio de autonomia dos institutos federais e sua política educacional em oposição à reforma do ensino médio. Jornal de Políticas Educacionais. V. 13, n. 10. Março de 2019.

IFMS. Projeto Pedagógico de Curso: Técnico em Eletrotécnica. Três Lagoas, 2019.

IFMS. Projeto Pedagógico de Curso: Técnico em Informática. Três Lagoas, 2019.

MARX, K. Instruções para os delegados do Conselho Geral Provisório: as diferentes questões. 1866 . Disponível em: https://www.marxists.org/portugues/marx/1866/08/instrucoes.htm. Acesso em: mar. 2021.

MARX, K. e ENGELS, F. Textos sobre Educação e Ensino. Campinas: Navegando, 2011.

MACHADO, L. Politecnia, Escola Unitária e Trabalho: Lições do passado e do presente. Trabalho Necessário; Ano 13, № 20/2015.

MOURA, D. H. A reforma do Ensino Médio: Regressão de direitos sociais. Revista Retratos da Escola,v. 11,n.20, p.109-129. Brasília jan/jun,2017.

RAMOS, M. N. Ensino Médio Integrado: Lutas históricas e resistências em tempos de regressão. In: Ensino médio integrado no Brasil: fundamentos, práticas e desafios /Adilson Cesar Araujo e Claudio Nei Nascimento da Silva (orgs.) - Brasilia: Ed. IFB, 2017.

RAMOS, M. N. Concepções do Ensino Médio Integrado. Disponível em: http://forumeja.org.br/go/sites/forumeja.org.br.go/files/concepcao_do_ensino_medio_integr ado5.pdf. Acesso em: jun. de 2021. 
SILVA, C. J. R. Institutos Federais Lei 11.892/2008. Comentários e Reflexões. IFRN editora. Brasília, 2009.

TRIBUNA DO NORTE NOTÍCIAS. IFRN questiona ausência dos Institutos Federais no resultado do Enem 2015. Disponível em: http://www.tribunadonorte.com.br/noticia/ifrnquestiona-ausa-ncia-dos-institutos-federais-no-resultado-do-enem-2015/360071. Acesso em: mai. de 2021.

\section{NOTAS}

\section{IDENTIFICAÇÃO DE AUTORIA}

Renata Moreira Delgado. Mestranda no Programa de Pós-Graduação em Educação (PPGEdu_CPTL) da Universidade Federal de Mato Grosso do Sul (UFMS). Instituto Federal de Educação, Ciência e Tecnologia de Mato Grosso do Sul, Três Lagoas, MS, Brasil.

E-mail: renata.delgado@ifms.edu.br

(D) https://orcid.org/0000-0002-1423-3740

Tarcísio Luiz Pereira. Doutor em Educação. Professor adjunto da Universidade Federal de Mato Grosso do Sul. Membro do Programa de Pós-Graduação em Educação (PPGEdu_CPTL) da Universidade Federal de Mato Grosso do Sul (UFMS). Três Lagoas, MS, Brasil.

E-mail: tarcisio.pereira@ufms.br

(D) https://orcid.org/0000-0002-2294-3742

\section{AGRADECIMENTOS}

Instituto Federal de Mato Grosso do Sul, Campus Três Lagoas (IFMS/TL)

\section{FINANCIAMENTO}

Não se aplica.

\section{CONSENTIMENTO DE USO DE IMAGEM}

Não se aplica.

\section{APROVAÇÃO DE COMITÊ DE ÉTICA EM PESQUISA}

Não se aplica.

\section{LICENÇA DE USO}

Autores mantêm os direitos autorais e concedem à revista ENSIN@ UFMS - ISSN 2525-7056 o direito de primeira publicação, com o trabalho simultaneamente licenciado sob a Licença Creative Commons Attribution (CC BY-NC-SA 4.0), que permite compartilhar e adaptar o trabalho, para fins não comerciais, reconhecendo a autoria do texto e publicação inicial neste periódico, desde que adotem a mesma licença, compartilhar igual.

\section{EDITORES}

Patricia Helena Mirandola Garcia, Eugenia Brunilda Opazo Uribe, Gerson dos Santos Farias.

\section{HISTÓRICO}

Recebido em: 03/08/2021 - Aprovado em: 02/11/2021 - Publicado em: 06/12/2021.

\section{COMO CITAR}

DELGADO, R. M; PEREIRA, T. L. O IFMS - Campus Três Lagoas - Contra a Reforma do Ensino Médio.

Revista ENSIN@ UFMS, Três Lagoas, v. 2, n. 6, p. 93-114. 2021. 